\title{
What Regulates Secretion of Non-Stored Proteins by Eukaryotic Cells?
}

\author{
Ann Marie Gebhart and Raymond W. Ruddon
}

\section{Summary}

Protein secretion is conventionally viewed as taking place by either of two cellular routes, a regulated pathway, involving external stimuli and secretory granules, and a presumptive 'constitutive' pathway, which does not involve hormonal or neuronal stimuli or the production of secretory granules. The evidence reviewed here strongly suggests that there are post-synthesis rate-limiting steps for many proteins released by the "constitutive' pathway and, hence, that regulation in some sense is involved here too. The nature of these rate-limiting determinants and events is discussed.

\section{Introduction}

The question posed in the title of this article implies a paradox. Indeed, it has been thought by some that proteins not packaged into secretory vesicles for later release or not directed to a specific intracellular organelle by some posttranslationally added signal (e.g. the mannose-6-phosphate modification of lysosomal enzymes) move through the cell via a continuous process that is essentially unregulated in the sense that it is passive and merely reflects 'bulk flow' of cellular material between intracellular compartments. Thus, in this view, the rate of secretion would be determined primarily by the rate of secretory protein synthesis. If this were the case, one would then expect that continuously secreted proteins, not stored in typical secretory vesicles for exocytosis in response to an external signal, would be secreted at the same or very similar rates as long as their biosynthetic rates were similar. We take the opposite point of view and will focus on the mechanisms of secretion of continuously secreted proteins and on potential mechanisms involved in regulation of their intracellular translocation and secretion.

\section{Protein Secretory Pathways}

Two general pathways are known to exist for the secretion of proteins from within the cell. The classic work of Palade and his colleagues ${ }^{1}$ on the pancreatic acinar cell, in which zymogen is stored in secretory vesicles and dependent on stimuli for secretion, typifies one type of secretory pathway. Secretion from pancreatic acinar cells is regulated by neuronal or hormonal signals. This secretory process is defined by several discrete events: (1) synthesis in the rough endoplasmic reticulum (RER), (2) translocation from RER to Golgi, (3) sorting and segregation in the Golgi, (4) concentration and storage in secretory vesicles, (5) translocation to the cell surface and (6) secretion. The second step, translocation of protein from the rough endoplasmic reticulum to the Golgi apparatus, is energydependent. The third event is where secretory products are sorted into different pathways for export. The next step, in which condensing vacuoles, presumably generated from the Golgi membranes, become mature secretion vacuoles, is not dependent on energy, but is dependent on intracellular ionic gradients. The final step, secretion, requires both energy and $\mathrm{Ca}^{2+}$, is stimulated by depolarization events at the plasma membranes and can proceed in the absence of protein synthesis. This so-called 'regulated pathway' is found in specialized secretory cells, such as exocrine and endocrine cells, neurons, neutrophils, and mast cells.

A second secretory pathway is observed in some cells, including fibroblasts, chondrocytes, liver parenchymal cells, macrophages, and B lymphocytes. In these cells, the concentration step is omitted, secretory granules are not found, and intracellular storage of proteins is diminished or omitted. This type of secretion is said to be continuous or 'constitutive'. In contrast to the regulated secretory pathway, the rate of secretion by the constitutive pathway is not dependent on hormonal or neuronal stimulation, cytoplasmic cyclic nucleotide levels or, in most cases, the integrity of colchicine-and cytochalasin-sensitive structures such as microtubules and microfilaments. ${ }^{2,3}$

Some cells are capable of processing secretory proteins by both types of pathways. An example is the AtT -20 cell line, a transformed mouse pituitary cell line in which the precursor of ACTH, pro-opiomelanocortin. (POMC), is cleaved into mature ACTH, which is then packaged into secretory granules and secreted upon stimulation of the cells with a secretagogue such as 8-bromoadenosine- $3^{\prime}, 5^{\prime}$-cyclic monophosphate (8 Br-cAMP). Some POMC is also secreted, but by a constitutive pathway that is insensitive to secretagogues that increase the release of ACTH. ${ }^{4,5}$ A summary of differences between the regulated and constitutive secretory pathway is shown in Table 1 .

The mechanisms involved in the regulated pathway have been recently reviewed. ${ }^{6}$ The observations that some cell types have both pathways, that the half-time for transport from the Golgi apparatus to the cell surface is long for proteins in the regulated pathways $\left(t_{\frac{1}{2}} \cong 10 \mathrm{~h}\right)$ compared to those translocated to the cell surface by the constitutive pathway $\left(t_{1} \cong 10 \mathrm{~min}\right)$, and that some proteins are retained in organelles along the pathway (e.g. cytochrome P-450 in the RER), while others proceed through the cell into specific organelles (e.g. lysosomes, secretory vesicles) indicate that a "sorting' mechanism exists in cells to direct translocated products into these different pathways. It should be noted that certain integral membrane proteins are also sorted and translocated to the cell surface via a constitutive mechanism that is similar to that of continuously secreted proteins.

For the regulated pathway, there is evidence to suggest that sorting occurs in the Golgi apparatus and that the molecular basis of this sorting depends on a 'sorting domain' of the secretory protein and on a 'carrier' that recognizes the sorting domain and directs the secretory protein into its correct secretory pathway. ${ }^{6}$ Transfection of recipient cells that have both the constitutive and regulated secretory pathways with genes encoding proteins destined to have regulated secretion in their parent (donor) cell type (e.g. pro-insulin, growth hormone, parathyroid hormone, 


\section{REVIEW ARTICLES}

$T A B L E I$. Summary of differences between the regulated and constitutive secretory pathways

\begin{tabular}{|c|c|c|}
\hline & Regulated & Constitutive \\
\hline 1 & $\begin{array}{l}\text { Secretory products } \\
\text { concentrated and stored } \\
\text { in secretory vesicles }\end{array}$ & $\begin{array}{l}\text { Concentration and storage } \\
\text { steps are missing }\end{array}$ \\
\hline 2 & $\begin{array}{l}\text { Secretory vesicles } \\
\text { microscopically observed } \\
\text { in cells }\end{array}$ & $\begin{array}{l}\text { Secretory vesicles not } \\
\text { observed }\end{array}$ \\
\hline 3 & $\begin{array}{l}\text { Limited to specialized } \\
\text { secretory cells }\end{array}$ & Occurs in all cell types \\
\hline 4 & $\begin{array}{l}\text { Secretion stimulated by } \\
\text { external secretagogues, e.g. } \\
\text { hormones and membrane- } \\
\text { depolarizing events }\end{array}$ & $\begin{array}{l}\text { Secretion is continuous and } \\
\text { not secretagogue-dependent }\end{array}$ \\
\hline 5 & $\begin{array}{l}\text { Secretion of stored } \\
\text { protein not dependent } \\
\text { on new protein synthesis }\end{array}$ & $\begin{array}{l}\text { Secretion parallels amount } \\
\text { of protein synthesized }\end{array}$ \\
\hline 7 & $\begin{array}{l}\text { Rate of secretory protein } \\
\text { translocation from Golgi } \\
\text { to cell surface is delayed } \\
\left(t_{\frac{1}{2}} \cong 10 \mathrm{~h}\right) \\
\text { Rate limiting step is } \\
\text { exocytosis }\end{array}$ & $\begin{array}{l}\text { Rate of secretory protein } \\
\text { translocation from Golgi } \\
\text { to cell surface is rapid } \\
\left.\text { ( } t_{1} \cong 10 \mathrm{~min}\right) \\
\text { Rate-limiting step is } \mathrm{RER}- \\
\text { Golgi translocation }\end{array}$ \\
\hline
\end{tabular}

and trypsinogen) has shown that these proteins are packaged into secretory vesicles and co-released with the recipient cells' endogenous, regulated secretory proteins upon stimulation with secretagogue. ${ }^{6}$ An implication of this finding is that proteins secreted via the regulated pathway should have a shared sorting domain amino acid sequence that would be involved in their recognition of the carrier. No such common amino acid sequence has been found so far, but carrier recognition sequences may be analogous to the signal peptides of proteins synthesized in the RER for export; these signal peptides also lack a common primary amino acid sequence homology, yet recognize a common signal peptide recognition particle.?

Based on a number of lines of evidence, it has been postulated that the regulated pathway has specific carriermediated intracellular translocation, whereas the constitutive pathway does not. 6,8 The evidence is as follows. (1) Treatment of At T-20 cells with the weak base chloroquine diverts ACTH from the regulated to theconstitutive pathway, suggesting that the latter pathway does not require specific signals. (2) Transfection of AtT-20 cells with DNA sequences encoding vesicular stomatitis virus (VSV) membrane protein (G protein) lacking the membrane spanning domain converts VSV-G protein into a secretory protein that is secreted selectively via the constitutive pathway, whereas the same cells transfected with the human growth hormone (hGH) gene co-secrete hGH with ACTH via the regulated pathway. (3) POMC, the viral membrane glycoprotein gp 70, and the extracellular matrix protein laminin are all translocated to the cell surface by AtT-20 cells via a constitutive mechanism with similar kinetics. These authors ${ }^{6}, 8$ thus postulate that the transport of secretory proteins in constitutively secreting cells is a passive, bulk flow mechanism not involving targeting information or carrier-mediated sorting. In this review, we would like to propose a different hypothesis, namely that the so-called constitutive pathway is in fact a regulated pathway, but that the regulation occurs at earlier steps in the intracellular translocation sequence than is the case for the 'regulated' pathway. It should be noted here that it: is likely that similar regulatory mechanisms occur in the pre-Golgi portions of both pathways and that the two pathways diverge in the Golgi.

\section{Translocation from RER to Golgi: Evidence for Regulated Steps in Continuously Secreting Colls}

Fittingand $\mathrm{Kabat}^{9}$ analysed the synthesis and kinetics of intracellular transport of two Friend murine leukemia virus (MuLV) membrane glycoproteins in virally infected mouse cells. The two glycoproteins, gp 70 and gp 93, although synthesized at similar rates, reach the cell surface at different rates. Maximum incorporation of gp 93 into the plasma membrane occurs at $60 \mathrm{~min}$ after initiation of chase in a pulse-chase experiment with $\left[{ }^{35} \mathrm{~S}\right]$ methionine, but gp 70 does not reach the cell membrane in detectable amounts until $90 \mathrm{~min}$ into the chase period. This difference is due to a slow step in gp 70 processing that coincides with proteolytic cleavage of the precursor of gp 70 . Gp 70 resides for a longer period of time in the RER than does gp 93. Since both of these proteins are translocated to the cell surface via a 'constitutive' pathway, these data argue against a strict passive flow process for this mechanism. These authors propose that plasma membrane proteins contain a signal in their amino acid sequence that mediates their export from the RER.

Lodish et al. ${ }^{10}$ studied the rates of secretion of five constitutively secreted proteins synthesized in cultured human hepatoma (Hep G2) cells. Half-times for secretion were shown to vary by as much as threefold. For example, 50\% of albumin and $\alpha_{1}$-antitrypsin is secreted in $45 \mathrm{~min}$ after biosynthetic labelling; half of the labelled $\mathrm{C} 3$ complement component and $\alpha_{1}$-antichymotrypsin are released in $85-90 \mathrm{~min}$, and half the labelled transferrin is secreted in $140 \mathrm{~min}$. The differences between the rates of secretion of these proteins appear to be due to the differences in rate of translocation from RER to Golgi, arguing against bulk flow between these two organelles and suggesting some selective, perhaps carrier-mediated event.

Yeo et al..$^{11}$ used cell fractionation techniques, lectin affinity, and sensitivity to the glycosidase endo $\mathrm{H}$, which cleaves primarily the high mannose-containing oligosaccharides found in glycoproteins localized in the RER, to examine the rates of intracellular translocation and secretion of transferrin, ceruloplasmin, and $\alpha_{1}$-antitrypsin by cultured human hepatoma cells. These three substrates are secreted at very different rates, have different half-times for translocation from RER to Golgi and, in addition, have different apparent rates of translocation through the Golgi.

Peters et al. ${ }^{12,13}$ have studied the rates of biosynthesis, processing, and secretion of chorionic gonadotropin (hCG) and laminin, two glycoproteins secreted continuously by cultured human choriocarcinoma (JAR) cells. Although the biosynthesis of these glycoproteins and the initial steps in their oligosaccharide processing occur at similar rates, their rates of release from the cell differ markedly. The half-time for release of hCG from JAR cells is $35 \mathrm{~min}$ and that of laminin $100 \mathrm{~min}$. Based on determination of the oligosaccharide composition, the rate-limiting step in 
REVIEW ARTICLES

release of hCG and laminin is translocation from RER to Golgi.

The intracellular transport of two highly homologous class I histocompatibility antigens, $\mathrm{H}-2 \mathrm{~K}^{\mathrm{k}}$ and $\mathrm{H}-2 \mathrm{D}^{k}$, has been determined in a murine $B$ cell lymphoma cell line by Williams et al. ${ }^{14}$ Newly synthesized $\mathrm{H}-2 \mathrm{~K}^{\mathrm{k}}$ reaches the cell surface within $1 \mathrm{~h}$, whereas $\mathrm{H}-2 \mathrm{D}^{\mathrm{k}}$ is transported much more slowly $\left(t_{1}=4-5 \mathrm{~h}\right)$ to the cell surface. The rates of translocation to the cell surface of these two glycoproteins parallel the rates at which their asparagine-linked oligosaccharides are processed to endo H-resistance, suggesting that the ratelimiting step is transport from RER to Golgi.

Taken together, these data are incompatible with a passive, bulk flow model for continuously or constitutively secreted molecules and suggest some type of substrate-specific process that regulates the rate of their secretion. The concept that the secretion of these substrates is regulated only by their rate of biosynthesis is also excluded by the results cited above.

\section{Characteristics of \\ Substrate-Specific Intracellular Translocation Events}

The rate-limiting event for a number of continuously secreted proteins appears to be translocation from RER to Golgi. Lodish et al ${ }^{10}$ have postulated that a receptor protein in the RER membrane regulates selective accumulation of secretory proteins into transport vesicles en route to the Golgi. Faster-migrating proteins might have a higher affinity for this receptor than slowly migrating proteins. An alternative explanation is that each secretory protein has its own receptor, each of which has a characteristic rate of incorporation into a transport vesicle. The amount of receptor in the RER membrane could be determined by the rate of synthesis and turnover of the receptor, its rate of incorporation into the RER membrane and its ability to cluster in the 'budding' area of RER membrane involved in vesicle formation. There is a precedent for this latter suggestion in receptormediated endocytosis, where attachment of a ligand to its receptor mediates clustering or patching of the receptors in the plasma membrane prior to formation of the endocytic vesicle. ${ }^{15}$

Recognition of such transport receptors could be via recognition signals determined by the polypeptide (either its primary amino acid sequence or conformation) or, in the case of glycoproteins,

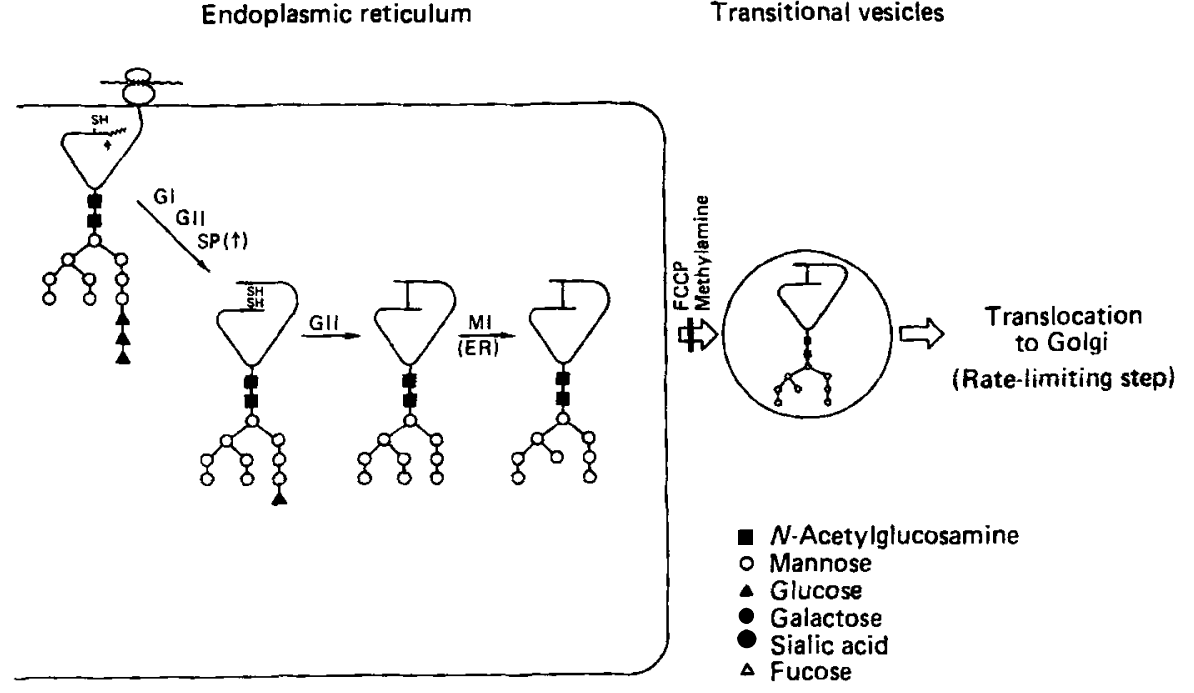

Golgi cisternae

Distal vesicles

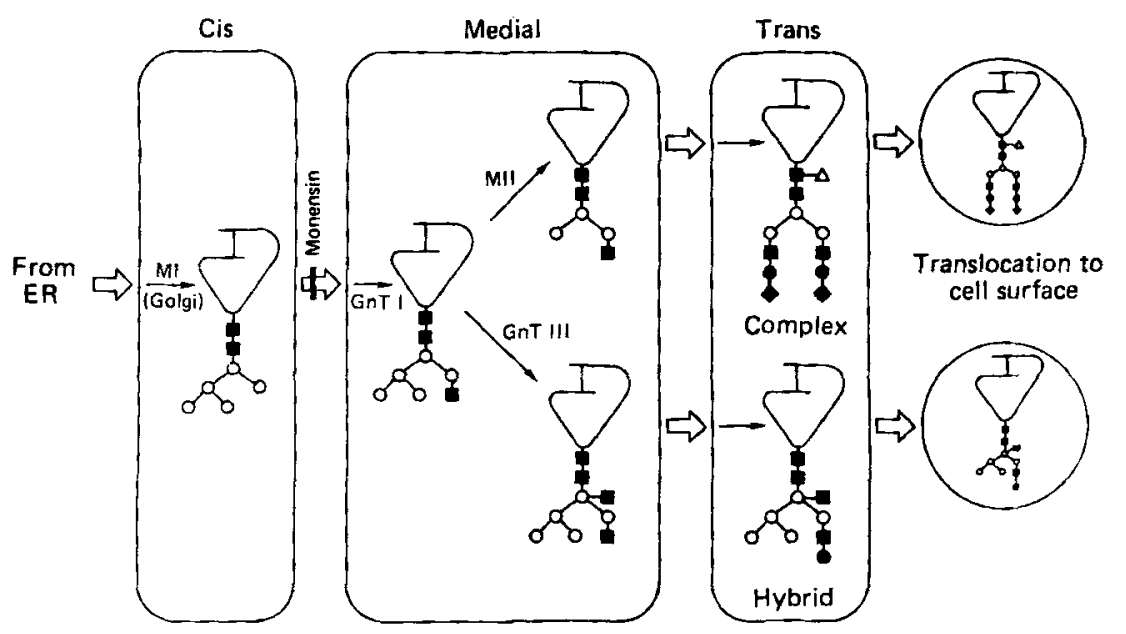

Fig. 1. Schematic representation of steps in the synthesis, processing and secretion of glycoproteins. The points at which FCCP, methylamine, and monensin block the intracellular translocation of glycoproteins are depicted. Processing enzymes include GI, glucosidase I; GII, glucosidase II; SP, signal peptidase; $M I$, mannosidase I (both RER and Golgi forms); MII, mannosidase II; GnT I, N-acetylglucosaminyl transferase I; GnT III, N-acetylglucosaminyl transferase III. Under certain conditions, such as inhibition of mannosidase II by swainsonine, ' hybrid' oligosaccharide chains may be formed and be present on secreted glycoproteins. (From Peters et al., ${ }^{23}$ with permission.)

either by the polypeptide or by the oligosaccharide structure or both. There is evidence that both protein and carbohydrate structure may be involved in translocation events for secretory proteins. For example, mutant genes encoding viral membrane glycoproteins of Rous sarcoma virus (RSV) and of VSV that are missing various portions of the transmembrane and cytoplasmic domains (i.e. the part of the polypeptide on the cytoplasmic as opposed to the cisternal face of the RER) have been transfected into cells and translocation and secretion of their respective gene products studied. ${ }^{16,17}$ The RSV mutant glycoproteins lacking the transmembrane and the cytoplasmic domains and
VSV glycoproteins lacking the cytoplasmic domain were retained in the RER and not translocated to the Golgi. These results suggest that the mutant proteins lack a translocating signal for transit to the Golgi.

Studies with glycosidase inhibitors suggest that for certain glycoproteins translocation signals may involve the structure of their oligosaccharides. The use of glycoproteins to study translocation events has the advantage that the glycosidases and glycosyltransferase involved in their synthesis and processing are distinctly compartmentalized in the RER and Golgi apparatus (Fig. 1). ${ }^{18}$ Thus the oligosaccharide composition of cellular glycoproteins serves as a 


\section{REVIEW ARTICLES}

$T A B L E I I$. Effects of various inhibitors of protein secretion

\begin{tabular}{|c|c|c|}
\hline Agent & Site of inhibition & $\begin{array}{l}\text { Effect on glycoprotein } \\
\text { translocation }\end{array}$ \\
\hline Tunicamycin & $\begin{array}{l}\text { Synthesis of lipid-carbohydrate } \\
\text { carrier complex for high mannose } \\
\text { asparagine-linked oligosaccharide }\end{array}$ & $\begin{array}{l}\text { Blocks secretion of some } \\
\text { but not all glycoproteins } \\
\text { and leads to their } \\
\text { retention in the RER }\end{array}$ \\
\hline 1-Deoxynojirimycin & Glucosidase I and II & $\begin{array}{l}\text { Retention of certain } \\
\text { glycoproteins in the RER }\end{array}$ \\
\hline N-methyldeoxynojirimycin & Glucosidase I and II & $\begin{array}{l}\text { Retention of certain } \\
\text { glycoproteins in the RER }\end{array}$ \\
\hline Castanospermine & Glucosidase I and II & $\begin{array}{l}\text { Retention of certain } \\
\text { glycoproteins in the RER }\end{array}$ \\
\hline Deoxymannojirimycin & Mannosidase I & $\begin{array}{l}\text { Slight or no inhibition } \\
\text { of glycoprotein secretion }\end{array}$ \\
\hline Swainsonine & Mannosidase II & $\begin{array}{l}\text { Slight or no inhibition } \\
\text { of glycoprotein secretion }\end{array}$ \\
\hline Monensin & Monovalent cation equilibrium & $\begin{array}{l}\text { Produces intra-Golgi block } \\
\text { of secretion }\end{array}$ \\
\hline Methylamine & Intracellular pH gradients & $\begin{array}{l}\text { Blocks RER-Golgi trans- } \\
\text { location }\end{array}$ \\
\hline FCCP & $\begin{array}{l}\text { Oxidative phosphorylation; } \\
\text { intracellular } \mathrm{pH} \text { gradients }\end{array}$ & $\begin{array}{l}\text { Blocks RER-Golgi trans- } \\
\text { location }\end{array}$ \\
\hline
\end{tabular}

marker of their intracellular location. Various drugs that have been shown to block oligosaccharide synthesis or processing have been utilized to examine glycoprotein translocation and secretion. The site of action of such drugs is shown in Table 2.

Tunicamycin is a drug that blocks addition of asparagine-linked ( $\mathrm{N}$-linked) oligosaccharide chains to glycoproteins by preventing formation of the dolichollinked $\mathrm{Glc}_{3} \mathrm{Man}_{9} \mathrm{GlcNAc}_{2}$ intermediate. Using this drug it has been shown that glycosylation is required for secretion of some glycoproteins such as IgA, IgE, and IgM from mouse plasmacytoma cells and $\alpha$-macroglobulin, $\alpha_{1}$-antitrypsin, and ceruloplasmin from human Hep G2 hepatoma cells (reviewed in ref. 19). Cell fractionation studies have shown that the nonglycosylated proteins remain in the RER. ${ }^{19}$ Additional evidence indicating a role for oligosaccharides in translocation and secretion of glycoproteins comes from studies with agents that block enzymes involved in trimming the carbohydrate chains, i.e. glucosidase $I$ and $I I$ and $\alpha$-mannosidase I and II. ${ }^{19,}{ }^{20}$ Treatment of Hep G2 cells with the glucosidase inhibitor 1-deoxynojirimycin blocks trimming of glucose residues from high-mannose oligosaccharides and inhibits translocation as well as secretion of $\alpha_{2}$-macroglobulin, ceruloplasmin, transferrin, and $\alpha_{1}$-antitrypsin by these cells but not translocation and secretion of albumin or VSV-G protein. The non-secreted glycoproteins accumulate in the RER, suggesting that trimming of the terminal glucose residues of $\mathrm{N}$-linked oligosacch- arides is a prerequisite for export of secretory glycoproteins from the RER. Similarly, the translocation of lysosomal enzymes cathepsin D and hexosaminidase from RER to Golgi is inhibited by 1-deoxynojirimycin in cultured human diploid fibroblasts. ${ }^{21}$

The best case for the involvement of oligosaccharides in translocation events comes from lysosomal enzymes that require formation of 6-phosphomannosyl groups on their N-linked oligosaccharide chains for transport to the lysosomes. Treatment of fibroblasts, for example, with tunicamycin or 1-deoxynojirimycin decreases the targeting of lysosomal hydrolases to lysosomes by preventing formation of the 6-phosphomannosyl group and causes their constitutive release from cells. ${ }^{19}$

Taken together, these results indicate that $\mathrm{N}$-linked oligosaccharides play an important regulatory role in the intracellular transport and secretion of glycoproteins and imply that a receptor or carrier involved in the RER-Golgi translocation recognizes either the carbohydrate moiety itself or a conformational structure imposed on the glycoprotein by the presence of the oligosaccharide.

\section{Role of lonic Gradients in Translocation and Secretion}

Agents that disrupt intracellular monovalent cation gradients in cells block intracellular translocation and secretion of a number of secretory proteins. For example, in a study of JAR choriocarcinoma cells, Peters et al. ${ }^{22,23}$ have shown that FCCP, methylamine, and monensin, three agents that collapse hydrogen ion gradients across cellular membranes by different mechanisms, inhibit oligosaccharide processing and secretion of hCG. FCCP and methylamine produce the accumulation of $\mathrm{Man}_{8-9} \mathrm{GlcNAc}_{2}$ by JAR cells. The accumulation of these precursors indicates blockade of RER to Golgi translocation (Fig. 1). On the other hand, monensin produces an intraGolgi blockade of translocation leading to the accumulation of $\mathrm{Man}_{5} \mathrm{GlcNAc}_{2}$-containing hCG subunits. CCCP, an analog of FCCP, also blocks RER-Golgi translocation of secretory proteins such as pancreatic zymogens, ${ }^{24}$ collagen, ${ }^{25}$ immunoglobulin, ${ }^{2}$ and thyroglobulin. ${ }^{26}$ Monensin has been shown to produce accumulation in the Golgi and to block secretion of a number of secretory proteins, including immunoglobulin, ${ }^{2}$ transferrin, ${ }^{27}$ fibronectin, ${ }^{28}$ procollagen, ${ }^{28}$ and viral membrane glycoproteins. ${ }^{27}$ Although a number of these agents also lower cellular ATP levels, it has been shown that effects on secretion and oligosaccharide processing can be achieved at concentrations that do not significantly lower ATP. ${ }^{23}$. Thus, these results implicate an important role for hydrogen ion gradients in regulating intracelhular translocation and secretion of proteins from cells.

\section{Translocation from the Golgi to Plasma Membrane}

It is this step that distinguishes most clearly the 'regulated' from the 'constitutive' secretory pathways. In the regulated pathway, the secretory products are stored in morphologically distinct secretory vesicles and are available for rapid release in response to an external signal. In the constitutive pathway, the translocation between Golgi and plasma membrane occurs continuously and relatively rapidly $\left(t_{1} \cong 10 \mathrm{~min}\right)$. Yet there must be some signals involved in the packaging of constitutively secreted products into vesicles and in the targeting of those vesicles to the appropriate place on the cell membrane where secretion can occur. Presumably this latter step involves a vesicle-plasma membrane fusion similar to that of the regulated pathway; however, as noted above, the constitutive pathway has several characteristics that distinguish it from the regulated type of exocytosis.

Although the most likely mechanism of transport of constitutively secreted 
REVIEW ARTICLES

products from the Golgi to plasma membrane is via vesicular traffic, such vesicles have not been definitely identified morphologically in cells or isolated by cell fractionation techniques. A new class of small vesicles, $150-200 \mathrm{~nm}$ in diameter, has been observed in VSVinfected Chinese hamster ovary (CHO) cells at the time of initial appearance of the VSV-G protein at the cell surface, suggesting that these vesicles may be involved in post-Golgi transport of VSV-G protein. ${ }^{28}$ Similar vesicles have been implicated in the transport of Semliki Forest Virus membrane glycoproteins from Golgi to cell surface. ${ }^{30}$ Whether these putative post-Golgi transport vesicles are in fact the organelles that carry out the exocytotic event in the constitutive secretory pathway awaits further study.

\section{Conclusion}

In this review we have taken the point of view that several sites of regulation are present in the intracellular translocation and secretion events of the so-called constitutive secretory pathway. The rate-limiting event in this pathway appears to reside primarily at the RER-Golgi translocation step, and there is considerable circumstantial evidence to indicate that this is a carrieror 'receptor'-mediated event requiring some specific signal or signals in either the protein or the carbohydrate (or both) structure of the secretory products. Additional points of regulation may occur during the 'shuttle' of secretory proteins between the cis, medial, and trans compartments of the Golgi. The Golgi-plasma membrane step in the constitutive pathway has not been well characterized. It most likely occurs by vesicle-mediated transport, but these vesicles have not been clearly identified. At any rate, the steps involved in secretion in continuously secreting cells clearly are regulated events, and secretion via the "constitutive' pathway depends on more than the rate of protein synthesis. Thus, in the broad sense, to call this an unregulated pathway is a misnomer.

\section{Acknowledgements}

The experimental results discussed in the text that originated from the authors' laboratory were supported by United States Public Health Service Grant CA-32949 awarded by the National Cancer Institute, Department of Health and Human Services. Linda
Harbison skillfully typed the manuscript.

\section{REFERENCES}

1 Palade, G. (1975). Intracellular aspects of the process of protein synthesis. Science 189, 347-358.

1 Tartakoff, A. M. \& Vassali, P. (1977). Plasma cell immunoglobulin secretion. Arrest is accompanied by alterations of the Golgi complex. J. Exp. Med. 146, 1332-1345.

3 TartakofF, A. M. \& Vassali, P. (1978). Comparative studies of intracellular transport of secretory proteins. J. Cell. Biol. 79, 694-707.

4 Gumbiner, B. \& Kelly, R. B. (1982). Two distinct intracellular pathways transport secretory and membrane glycoproteins to the surface of pituitary tumor cells. Cell 28, 51-59.

5 MoORE, H.-P. H., Gumbiner, B. \& KelLy, R. B. (1983). Chloroquine diverts $\mathrm{ACTH}$ from a regulated to a constitutive secretory pathway in AtT-20 cells. Nature 302, 434-436.

6 Kelly, R. B. (1985). Pathways of protein secretion in eukaryotes. Science 230, 25-32. 7 BLOBEL, G. (1980). Intracellular protein topogenesis. Proc. Natl. Acad. Sci. USA 77, $1496-1500$.

8 MOORE, H.-P. H. \& Kelly, R. B. (1985). Secretory protein targeting in a pituitary cell line: differential transport of foreign secretory proteins to distinct secretory pathways. J. Cell Biol. 101, 1773-1781.

9 FitTING, T. \& KaBAT, D. (1982). Evidence for a glycoprotein 'signal' involved in transport between subcellular organelles. $J$. Biol. Chem. 257, 14011-14017.

10 LODISH, H. F., KONG, N., SNIDER, M. \& Strous, G. J. A. M. (1983). Hepatoma secretory proteins migrate from rough endoplasmic reticulum to Golgi at characteristic rates. Nature 304, 80-83.

11 Yeo, K.-T., Parent, J. B., Yeo, T.-K. \& OLDEN, K. (1985). Variability in transport rates of secretory glycoproteins through the endoplasmic reticulum and Golgi in human hepatoma cells. J. Biol. Chem. 260, 7896-7902.

12 Peters, B. P., Krzesicki, R. F., Hartle, R. J., Perini, F. \& Ruddon, R. W (1984). A kinetic comparison of the processing and secretion of the $\alpha \beta$ dimer and the uncombined $\alpha$ and $\beta$ subunits of chorionic gonadotropin synthesized by human choriocarcinoma cells. J. Biol. Chem. 259, 15123-15130.

13 Peters, B. P., Hartle, R. J., Krzesicki, R. F., Kroll, T. G., Perini, F., Balun, J. E., Goldstein, I. J. \& Ruddon, R. W. (1985). The biosynthesis, processing, and secretion of laminin by human choriocarcinoma cells. J. Biol. Chem. 260, 14732-14742. 14 Williams, D. B., SwiedleR, S. J. \& HART, G. W. (1985). Intracellular transport of membrane glycoproteins: two closely related histocompatibility antigens differ in their rates of transit to the cell surface. J. Cell Biol. 101, 725-734.

15 Pastan, I. H. \& Willingham, M. C. (1981). Journey to the center of the cell: role of the receptosome. Science 214, 504-509. 16 Willis, J. W., SRinivas, R. V. \& HunTeR, E. (1984). Mutations of the Rous sarcoma virus env gene that affect the transport and subcellular location of the glycoprotein products. J. Cell Biol. 99, 2011-2023.

17 Gabel, C. A. \& Bergmann, J. E. (1985) Processing of the asparagine-linked oligosaccharides of secreted and intracellular forms of the vesicular stomatitis virus $G$ protein: in vivo evidence of Golgi apparatus compartmentalization. J. Cell Biol. 101, $460-469$

18 Dunphy, W. G. \& Rothman, J. E. (1985). Compartmental organization of the Golgi stack. Cell 42, 13-21.

19 Olden, K., Bernard, B. A., Humphries, M. J., YeO, T.-K., YeO, K.-T., White, S. L. Newton, S. A., Bauer, H. C. \& Parent, J. B. (1985). Function of glycoprotein glycans. TIBS 10, 78-82.

20 Schwarz, R. T. \& Datema, R. (1984). Inhibitors of trimming: new tools in glycoprotein research. TIBS 9, 32-34.

21 Lemansky, P., GieselmanN, V., Hasilik A. \& von Figura, K. (1984). Cathepsin D and $\beta$-hexosaminidase synthesized in the presence of 1-deoxynojirimycin accumulate in the endoplasmic reticulum. J. Biol. Chem. 259, 10129-10135.

22 Peters, B. P., Brooks, M., Hartle, R. J., Krzesicki, R. F., Perini, F. \& RudDON, R. W. (1983). The use of drugs to dissect the pathway for secretion of the glycoprotein hormone chorionic gonadotropin by cultured human trophoblastic cells. J. Biol. Chem. 258, 14505-14515.

23 Peters, B. P., Krzesicki, R. F., Perini, F. \& RuDdon, R. W. (1986). The effects of FCCP and methylamine on the processing and secretion of the glycoprotein hormone chorionic gonadotropin by human choriocarcinoma cells. Endocrinology (in press).

24 Jamieson, J. D. \& Palade, G. E. (1968). Intracellular transport of secretory proteins in the pancreatic exocrine cell. IV. Metabolic requirements. J. Cell Biol. 39, 589-603.

25 Kruse, N. J. \& Bornstein, P. (1975) The metabolic requirements for transcellular movement and secretion of collagen. J. Biol. Chem. 250, 4841-4847.

26 Godelaine, D., Spiro, M. J. \& Spiro, R. G. (1981). Processing of the carbohydrate units of thyroglobulin. J. Biol. Chem. 256, 10161-10168.

27 Strous, G. J. A. M. \& Lodish, H. F. (1980). Intracellular transport of secretory and membrane proteins in hepatoma cells infected with vesicular stomatitis virus. Cell 22, 709-717.

28 UCHDd, N., SmILowitz, H., LedGer, P. W. \& TANZER, M. L. (1980). Kinetic studies of the intracellular transport of procollagen and fibronectin in human fibroblasts. J. Biol. Chem. 255, 8638-8644.

29 BergmanN, J. \& SINGER, S. (1983). Immunoelectron microscopic studies of the 


\title{
REVIEW ARTICLES
}

intracellular transport of the membrane glycoprotein $(G)$ of vesicular stomatitis virus in infected Chinese hamster ovary cells. $J$. Cell Biol. 97, 1777-1787.

30 Saraste, J. \& Kuismanen, E. (1984). Pre- and post-Golgi vacuoles operate in the transport of Semliki Forest virus membrane glycoproteins to the cell surface. Cell 38, 535-549.
ANN MARIE GEBHART AND

RAYMOND W. RUDDON are in the

Department of Pharmacology, University of

Michigan Medical School, Ann Arbor, MI 48109, USA.

\section{Role of Mammalian Circular DNA in Cellular Differentiation}

\author{
Hideo Yamagishi
}

\section{Summary}

The presence of small polydisperse extrachromosomal circular (spc) DNAs composed entirely of chromosomal sequences seems to reflect the plasticity of eukaryotic genomes. The size distribution and number of spc DNAs is found to vary with development, growth state and mitotic capacity. In particular, spc DNAs are observed to be several fold smaller in established immortal cell lines than in diploid cells with a limited life span. Analysis of cloned spc DNA fragments revealed that: (1) most of the spc DNAs thus far investigated contain repetitive sequences; (2) some of the repetitive sequences are enriched in spc DNA clones relative to their representation in the chromosome; (3) various repetitive sequences of different reiteration frequency were found in spc DNA from immortal cell lines while a particular sequence of retroyoson was predominant in primary lym shoid tissue cells and stem cells; (4) most of these spc DNAs appear to represent the extra copies generated by replicon-misfiring in immortal cell lines or by retrotranscription in stem cells, and intermediates or by-products produced by abortive rearrangement in diploid cells with a finite replicative capacity.

\section{General Features of spc DNA}

Many eukaryotic cells have been shown to contain spc DNAs with a heterogeneous size distribution of from $0 \cdot 1$ to more than $2 \mu \mathrm{m}(6 \mathrm{~kb}) .{ }^{1}$ Recently, a larger ill-defined population of spc DNA ranging in size to more than $150 \mathrm{~kb}$ has been isolated from mouse thymocytes. ${ }^{2}$ The common features of spc DNA populations are (1) chromosomal origin and (2) heterogeneity in size, total number per cell and nucleotide sequence. $^{3}$ In mammalian cells, spc DNA was found in both fractions of karyoplasts and cytoplasts. ${ }^{4}$ By these criteria, spc DNA can be distinguished from organelle DNAs, plasmids and viral DNAs.

\section{Size Distribution and Copy Number of spe DNA}

Extrachromosomal circular DNAs may be present in the form of covalently closed circular (ccc) DNAs. However, the conventional method for isolating covalently closed circular (ccc) DNAs is a time-consuming and a large-scale process. Recent methodological developments involving mica-press-adsorption allowed rapid microscale visualization of spc DNAs and semi-quantitative measurements of the size distribution and the number per cell., 4

Most, if not all, spc DNAs observed by the mica-press-adsorption method were attached to a bit of protein or to membrane fragments. The spc DNA thus examined may be linear with their two ends linked by proteins or membrane material and stabilized by forming a complex. Comparative studies on small circular DNAs isolated by different methods, the conventional dye-buoyant- density method for authentic ccc DNA and the mica-press-adsorption method for the spc DNA/protein complex, were performed. The size distribution and the copy number of small circular DNAs estimated by these two different methods were very similar. Most spc DNA/protein complexes seem to represent authentic small circles. ${ }^{4}$

Every eukaryotic cell studied so far has contained spc DNAs. Their size distribution and copy number are found to vary, depending on the cell source (Table 1) ${ }^{1,4-7}$ The number average of contour length is more than $2 \mu \mathrm{m}$ for primary lymphoid tissue cells, $1-2 \mu \mathrm{m}$ for secondary lymphoid tissue cells and primary cell lines, $0 \cdot 3-1.0 \mu \mathrm{m}$ for immortal cell lines, and less than $0.3 \mu \mathrm{m}$ for embryonic stem cells. Every cell source can be grouped further arbitrarily into two large classes by the threshold value of $1 \mu \mathrm{m}$ in average contour length. Spc DNAs were several fold larger in primary cell lines and cells in situ than in transformed cell lines and embryonic cells. Copy numbers of spc DNA appear to be less in primary cell lines and cells in situ than in transformed cell lines and embryonal carcinoma (EC) cells. Speci-

TABLE I. Properties of spc DNA examined by mica-press-adsorption ${ }^{1,4-7}$

\begin{tabular}{lccc}
\hline Cell source* & $\begin{array}{c}\text { Average size } \\
(\mu \mathrm{m})\end{array}$ & $\begin{array}{c}\text { Fraction of spc DNA } \\
\text { of more than 1 } \mu \mathrm{m}(\%)\end{array}$ & $\begin{array}{c}\text { Total number } \\
\text { per cell }\end{array}$ \\
\hline $\begin{array}{l}\text { Primary lymphoid } \\
\text { tissue cell }\end{array}$ & $1 \cdot 9-5.4$ & $80-90$ & $100-200$ \\
$\begin{array}{l}\text { Secondary lymphoid } \\
\text { tissue cell }\end{array}$ & $1 \cdot 0-1 \cdot 8$ & $40-50$ & $50-130$ \\
$\begin{array}{l}\text { Primary cell line } \\
\text { Immortal cell line }\end{array}$ & $1 \cdot 0-2.0$ & $30-60$ & $20-50$ \\
Embryonic cell & $0 \cdot 3-1 \cdot 0$ & $\sim 25$ & $400-1200$ \\
& $\sim 0.3$ & $3-10$ & $100-600$
\end{tabular}

\footnotetext{
* Primary lymphoid tissue cell (mouse thymus, bone marrow; chick thymus, bursa): Secondary lymphoid tissue cell (mouse spleen, spleen T-cell, lymph node): Primary cell line (human lung; mouse liver; chick retina): Immortal cell line (human HeLa; mouse 3T6, L; rat L6): Embryonic cell (mouse F9, 311, early embryo before compaction).
} 